PREFACE

\title{
Navigating Bureaucratic Imprecision in the Search for an Accurate Count of Latino/a Military Service in World War II
}

\author{
KARL ESCHBACH AND MAGGIE RIVAS-RODRIGUEZ
}

When twenty-five-year-old Trinidad Botello, from the small central Texas community of San Saba, was discharged from the U.S. Army in fall 1945, a clerk recorded his particulars: brown eyes, black hair, 5 feet, 5 inches, 145 pounds, U.S. citizen. Under "Race," where only three choices were offered-“White," "Negro," and "Other (specify)"-the clerk typed "Mexican."

The following year, his younger brother, Crisantos D. Botello, was discharged from the U.S. Army. His particulars were almost identical: brown eyes, black hair, 5 feet, 5 inches, 140 pounds, U.S. citizen. But under "Race," this clerk typed "White."

In fact, there were five Botello brothers who served in World War II. Besides Trinidad and Crisantos there was John, who was inducted in summer 1943 and discharged in November 1945; Simon, sworn in November 1942 and discharged in summer 1946; and Gregorio, who joined the navy and was discharged in 1945. Simon was categorized as "White," John as "Mexican," and Gregorio as "White." So three of the five brothers were considered white and two, Mexican.

The Botello brothers' discharge papers illustrate the capriciousness of Latina/o racial categorization in that period. Because of a bureaucratic idiosyncrasy, the racial assignments of Mexican Americans and other Latina/os were inconsistent throughout World War II and to this day continue to bedevil demographers, public policy makers, historians, and even family members. ${ }^{2}$ The irony of fluid racial assignments got the attention of World War II veterans. For instance, in one interview in 2000 a veteran from West Texas recalled being prodded by a drill instructor to answer whether he was Spanish or Mexican. Aniceto "Cheto" Nuñez recalled, "I told him, 'I was Mexican, but when the war started I became a white man." The instructor persisted, Mexican? "No, I was not born in Mexico," replied Nuñez. "I 


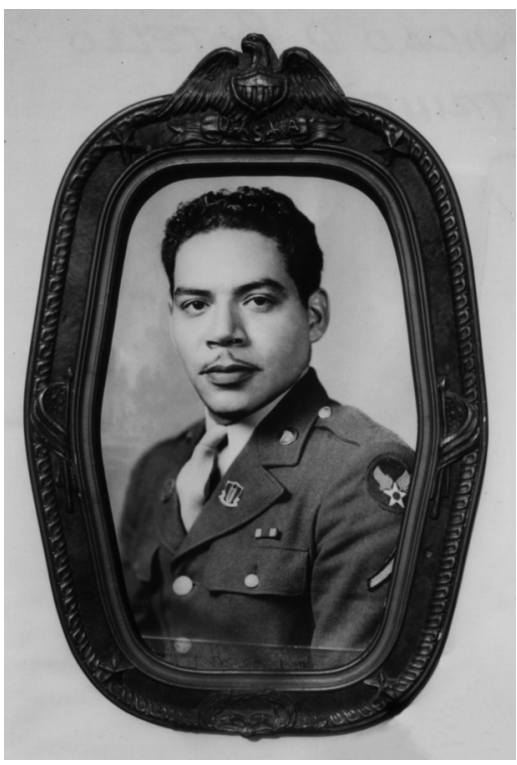

Figure 0.1. Trinidad D. Botello, one of five Botello brothers from San Saba, Texas, was identified as "Mexican" by U.S. Army officials. Voces Oral History Project, Nettie Lee Benson Latin American Collection, University of Texas at Austin.

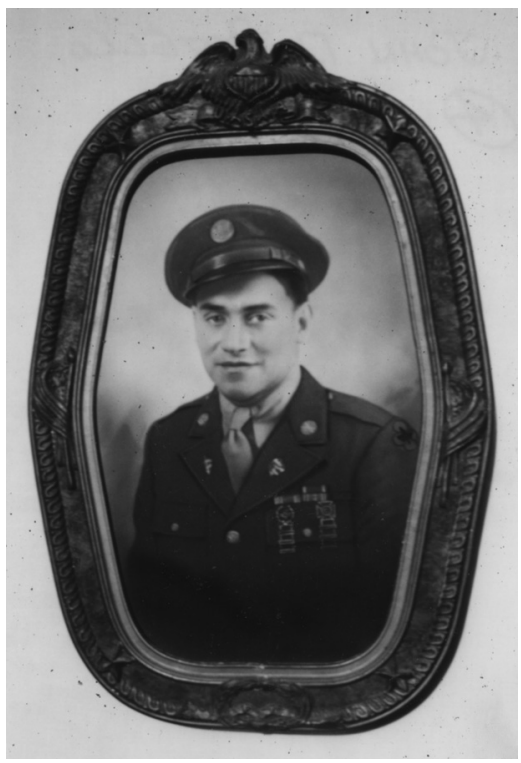

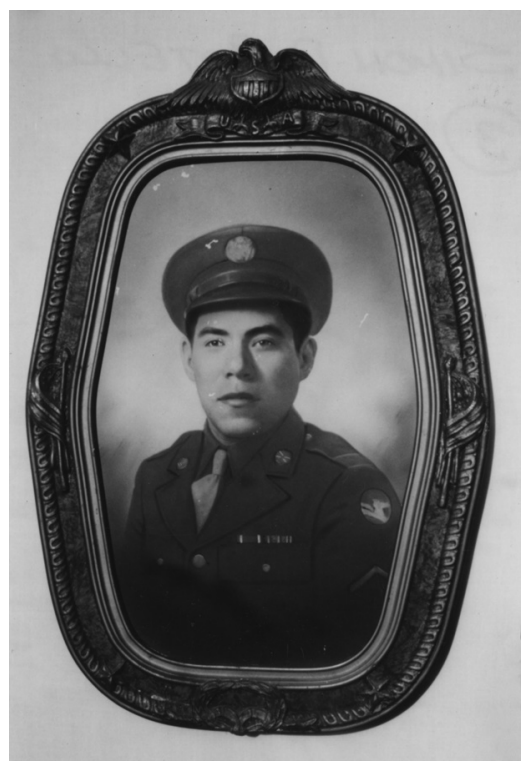

Figure 0.2. Simon D. Botello was classified as "white" on his discharge papers. Voces Oral History Project, Nettie Lee Benson Latin American Collection, University of Texas at Austin.

Figure 0.3. John D. Botello was listed as "Mexican" on his discharge papers. Voces Oral History Project, Nettie Lee Benson Latin American Collection, University of Texas at Austin. 


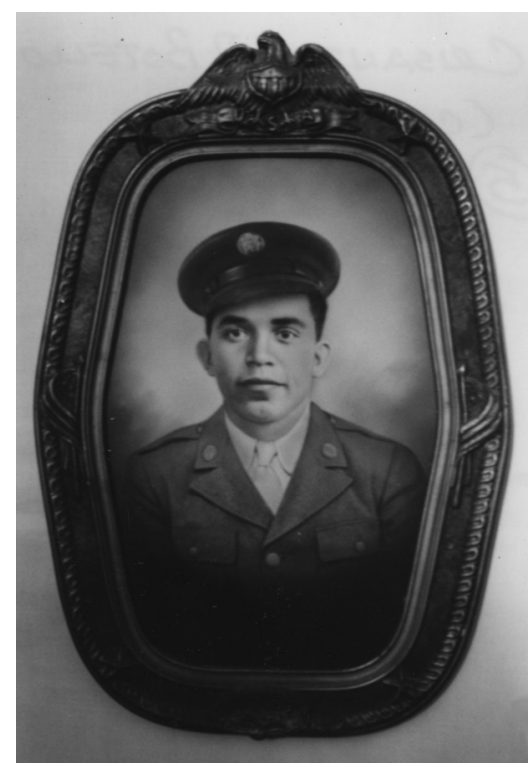

Figure 0.4. Crisantos D. Botello was categorized as "white." Voces Oral History Project, Nettie Lee Benson Latin American Collection, University of Texas at Austin.

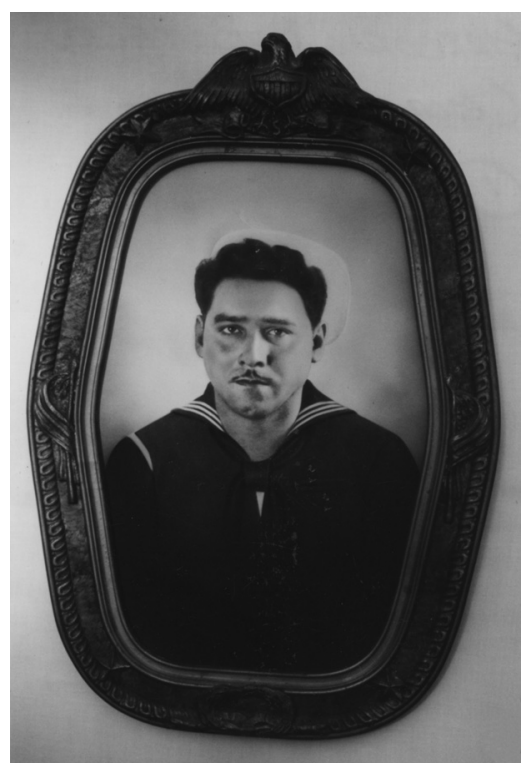

Figure 0.5. Gregorio D. Botello was considered "white" by navy officials. Voces Oral History Project, Nettie Lee Benson Latin American Collection, University of Texas at Austin.

was born in Fort Stockton, but they called me Mexican. And when the war started, I became a white man."

Because of the unreliability of racial categorization, the question of Latino participation in the military during World War II has long been a matter of debate and conjecture. The total number of servicemen in World War II was well established: 16.1 million. That number was easily accessible from the federal government. It is known, for instance, that Americans categorized as "Negro" made up nearly one million military personnel during World War II, serving in segregated units. ${ }^{4}$ But in fact those "Negro units" included some Hispanics. ${ }^{5}$ Native Americans in the military totaled 21,767. Bernstein notes:

Indeed because the Indian soldiers did not serve in segregated units like their black counterparts, it is even difficult to trace the pattern of participation. Nevertheless, the involvement of thousands of young Indians in the military during World War II signaled a major break with the past for In- 
dians and whites alike. It represented the first large-scale exodus of Indian men from the reservations since the defeat of their ancestors, and an unparalleled opportunity to compete in the white world in an arena where their talents and reputation as fighters inspired respect. ${ }^{6}$

Japanese Americans numbered 33,000 in World War II, ${ }^{7}$ Chinese Americans around $13,000 .^{8}$ Although the numbers may suffer similarly from inaccuracy, it is likely that these soldiers were entered as Indian, Native American, or Japanese or Chinese Americans on their enlistment and discharge papers. Latina/os were another matter, as shown in the example of Mexican American soldiers. The situation was even more complicated for other Latinos. Puerto Ricans, U.S. citizens since 1917, were drafted and often assigned to the segregated Third Battalion of the 65 th Infantry Regiment and the National Guard unit of the 295th Infantry Regiment. As Silvia Álvarez Curbelo has noted, the disconnect between the island's and the mainland's interpretation of race emerged: “The 'White' category handled by the Puerto Rican boards did not always conform with the popular version of the term in the United States. It included Puerto Ricans who were considered 'White' on the island but who would be seen as "colored' elsewhere." On the mainland, Latinos in general were not as easily identified: there were no clear demarcations between "Whites" and "Mexicans."

Some public and scholarly estimates of Latina/o participation in World War II reported figures without providing their provenance, making it impossible to determine their validity. ${ }^{11}$ Yet it is important to pursue the question of an accurate number as it conveys in general terms the participation of Latina/os among the 16 million men and women who served in the armed forces during World War II. For academics and the media, the numbers are crucial for assessing the extent to which the war effort included Latina/os-beyond the anecdotal. Research that includes statistical information is deemed more legitimate, more credible; enumeration may reveal a problem or show areas that require greater attention. ${ }^{12}$

To tackle the question of the number of Latina/os who served in the U.S. military during the war, we turned to information from the U.S. Census. But we immediately recognized some of the limitations and potential for under- or even overreporting. Among the challenges were changes in how the Census Bureau counts residents of Hispanic/Latina/o descent and migration of Latina/os from the mainland or Puerto Rico or other countries. Still the census is a good starting point: over the course of more than two hundred years of data collection, it has gathered information on military service sporadically. In 1950, four years after the end of World War II, 
the census included a question about service in the U.S. military and period of service in a sample count; that is, not all households were asked this question. In the censuses of 1960 through 2000 the veteran status question has been included on the so-called long form of the census, which collects detailed socioeconomic data from persons in a large sample of U.S. households.

In 1980 the census asked the following question about veteran status: "Is this person a veteran of active-duty military service in the Armed Forces of the United States?" Those who responded yes were asked, "Was active duty military service during ..." Among the response categories were "World War II (September 1940-July 1947)," "May 1975 or later," "Vietnam Era," "February 1955-July 1964," "Korean Conflict," "World War I," and "Any other time." More recent censuses have included a similarly worded question. ${ }^{13}$

This question implements a classification of veteran status and period of service by self-identification. It is not validated by cross-checking against administrative service records, though errors introduced by self-report are likely small. It is a general measurement: the question does not include information about service in a combat unit, overseas deployment, or actual combat experience. Nonetheless, it provides a reasonable basis for a count of veterans on active duty for each service period and is used by the Veteran's Administration as the basis for its population model of the demographic characteristics of the veteran population of the United States. ${ }^{14}$

But a breakdown of the racial demographics of the veteran population using the 1950 and 1960 censuses still did not enable a determination of the Latina/o component. In 1930 the Census Bureau created the category "Mexican" but then discontinued it and did not include a question about membership in a Latina/o-descent population for forty years. In $1970 \mathrm{a}$ sample of the population was asked a question about "origin or descent," with response categories focused on Latina/o origins. And in the following decennial census and subsequently, all respondents to both the short form and long form census schedule have been asked to report "Spanish/Hispanic" origin. ${ }^{15}$

In 1980 respondents were asked to classify themselves and their household members in response to the question, "Is this person of Spanish/Hispanic origin or descent?" Response categories included "Mexican, MexicanAmer., Chicano," "Puerto Rican," "Cuban," "other Spanish/Hispanic," and "No, not Spanish/Hispanic." Since 1980 this question or minor variations of it have been used to identify the "Hispanic" population of the United States in the federal statistical system. It implements the system of using 
Table 0.1. Latino World War II Veteran Population Counted in the United States Census, 1970-2000

\begin{tabular}{ccccc}
\hline Year & Men & Women & Total & 95\% Confidence Interval \\
\hline 1970 & 289,000 & NA & $289,000^{\dagger}$ & $283,951-294,049^{\dagger}$ \\
1980 & 262,960 & 6,020 & 268,980 & $263,666-274,294$ \\
1990 & 201,881 & 4,941 & 206,822 & $200,996-212,648$ \\
2000 & 134,987 & 4,469 & 139,456 & $132,758-146,154$ \\
\hline
\end{tabular}

${ }^{\dagger}$ Males only.

Source: Integrated Public-Use Microdata Project at the University of Minnesota, relying on U.S. censuses.

self-identification as the preferred way to classify persons in relation to racial and ethnic category membership. ${ }^{16}$

Thus each census from 1970 through 2000 gives a full, large sample estimate of the population that lived in the United States (including Puerto Rico), identified themselves as "Spanish or Hispanic," and reported active duty service in the U.S. military in the World War II era. But those counts had limitations similar to those of any census or survey: sampling error, undercount, and out-migration of the target population from the coverage area of the census. Moreover, the 1970 census did not include women in its count of veterans. It is also known that the wording of the question in the 1970 sample produced a smaller estimate of the U.S. Hispanic population than would have been the case with the wording used at the later censuses and in particular undercounted Mexican Americans. ${ }^{17}$

Table 0.1 shows these estimates, as reported from data in the Integrated Public-Use Microdata Project at the University of Minnesota, a probability sample of records from each census. Confidence intervals are reported based on information about item-specific design effects on standard errors reported at the time each data set was prepared.

How do these counts relate to an estimate of the number of Latina/o veterans who served in the U.S. military? We were lacking a key variable: how many Latina/o service personnel died between their entry into service and the day the census was taken? We needed to produce two numbers: (1) how many military personnel died during the period of service itself and (2) how many died from the end of the war until the date of the census-a period of approximately twenty-five years, reckoning from August 1945 (VJ Day) to April 1970 (the reference day for the U.S. Census in 1970), and then fiftyfive years, to April 2000, the reference day for the final census. 
The number of deaths in the postwar period may be estimated with some precision from information produced by the National Center for Health Statistics (NCHS) and predecessor agencies over the entire period. Each decade the NCHS produces a life table for the U.S. population by sex and for the white and black populations. These tables use registered deaths for the three years centered on each census, together with counts of population from the census, to calculate age- and sex-specific schedules of death rates for each population. ${ }^{18}$ With this information, it is possible to produce estimates of deaths occurring in the intervals between the end of hostilities in 1945 and subsequent censuses, applying across each decade the mortality schedule derived for each period.

Some uncertainty is introduced because the age-specific death rates of the U.S. population as a whole may not apply directly to the population of Latina/o veterans. Other studies had shown that specific service experiences-such as exposure to combat and service in particular theaterswas linked to increased mortality among veterans after the war. But active duty status per se was not predictive of subsequent mortality, which we determined after we considered the countervailing effects of health selection in the veteran population and the negative effects of service. ${ }^{19}$ Analyses of Hispanic mortality patterns have also shown that, with some differences in age patterns of mortality, Hispanic mortality rates are similar to or slightly lower than those of non-Hispanic whites. ${ }^{20}$ It may be necessary to be sensitive to departures from average mortality schedules for the U.S. population. However, given what is known about Hispanic mortality and veteran mortality, we may make corrections of plausible magnitudes and still arrive at only modest increases in uncertainty about the size of the serving Latina/o population. That is to say, our estimates, after allowing for differences in both Hispanic and veteran mortality, should have only a nominal effect on our certainty.

Data suggest that the number of deaths from both combat and noncombat causes of active duty personnel during World War II was 2.5 percent of all active duty personnel. ${ }^{21}$ Because records of deaths are not available for Latina/o servicemen and servicewomen, additional uncertainty is introduced about the exact size of the serving population. However, it is the case here as well that plausible increases or decreases in the active duty death rate for Latina/os compared to other groups would lead to a correction in the estimate of the total serving population in the range of a few thousand persons. One issue that cannot be ascertained at this time is whether those active duty death rates were higher in certain units and whether Latina/os were overrepresented in those units. 
Table 0.2. Estimates of the Number of Latinos Who Served on Active Duty during World War II Derived from Census Counts of Veterans, 1970-2000

\begin{tabular}{cccc}
$\begin{array}{c}\text { Estimate Based } \\
\text { on Census } \\
\text { of Year }\end{array}$ & $\begin{array}{c}\text { Point Estimate of } \\
\text { Veteran Population } \\
\text { Alive in 1945 }\end{array}$ & $\begin{array}{c}\text { Adjustment for } \\
\text { Deaths during } \\
\text { Active Service }\end{array}$ & 95\% Confidence Interval \\
\hline \multirow{2}{*}{1970} & $328,000^{+}$ & $336,500^{+}$ & $330,600-342,300^{+}$ \\
1980 & 363,000 & 372,400 & $365,000-379,700$ \\
1990 & 359,000 & 368,300 & $358,900-378,600$ \\
2000 & 351,000 & 360,100 & $342,800-377,400$ \\
\hline
\end{tabular}

${ }^{\dagger}$ Males only.

Source: Census figures, authors' estimates, after weighing mortality rates for general military serviceman population.

Estimates of the number of Latina/os who served in World War II derived by these methods from subsequent census counts are presented in $\mathrm{Ta}^{-}$ ble 0.2 . These estimates are remarkably concordant over time, suggesting a Latina/o World War II service population in the range of 340,000 to 380,000 .

Further adjustment of these estimates may be warranted, though the size of the adjustment is speculative. An adjustment for census undercount may be warranted. The 1970 count of Latina/os was certainly low, primarily because of question wording. The size of the correction is not known. ${ }^{22}$ The Census Bureau estimated a net undercount of Hispanics in 1990 of approximately 5 percent and a net undercount in 2000 of 0.71 percent, the latter not significantly different from 0 percent. ${ }^{23}$ It is likely that much of the apparent reduction in undercount between 1990 and 2000 was attributable to the change in the Census Bureau methodology for estimating undercount. In any case, the undercount of Hispanics in recent U.S. censuses has been attributed to the presence of the hard to enumerate undocumented immigrant population as part of the Hispanic population. ${ }^{24}$ However, the World War II veteran population was overwhelmingly a citizen population by birth or naturalization by the time of the census counts. It is unlikely that this population was undercounted to the same degree as were younger immigrants.

A second source of underestimation would result from substantial emigration of Latina/o veterans from the United States and Puerto Rico between the end of the war and the census. We know from each census itself that approximately 1 percent of Latina/o World War II veterans reported 
living outside of the enumeration area five years before the census was taken. The largest proportion (1.5 percent) report this in 1970, when the number may have been elevated by World War II veterans who were career soldiers on active duty status in Vietnam or in other overseas deployment in 1965.

It is likely that at least a few Latina/o U.S. military veterans migrated to another country. This would have been most likely for foreign-born servicemen who chose to return to a country of origin in the years immediately after the war. As the cohort aged, retirement to areas with cheaper costs of living and more favorable climates, such as Mexico or elsewhere in Latin America, may have been seen as attractive, which is a choice made by some Americans of all racial and ethnic backgrounds. For the many Latina/o veterans who were near-border residents, such relocations may be minimally disruptive. Nonetheless, it should be recognized that net migration flows between Mexico, Latin America, and the United States in the postwar period were overwhelmingly from south to north. A substantial majority of Latina/os serving in active duty during World War II were born in the United States. An overwhelming majority of Latina/o veterans were U.S. citizens in the years after the war. These considerations suggest that outmigration of World War II veterans from the United States has had small effects on these estimates.

Probably the most important source of potential underestimation comes from changing self-definitions of ethnicity over time. For example, Alba and Islam estimated that approximately 10 to 15 percent of the Mexicanorigin population disappeared from census counts between 1980 and 2000 because of changing self-definition of ethnicity. ${ }^{25}$ This decrease may partly account for the slightly lower estimates of the size of the Latina/o veteran population derived from the 2000 census compared to the 1980 census as presented here. But it is also possible that similar attrition would have occurred between the war and the census counts used to make these estimates. From the point of view of census enumerations, this is a hypothetical question, because Latina/o identity choices were not available on census counts before 1970. In other words, an unknown portion of the Latina/o veteran population may have chosen not to report its ethnicity when filling out the census, even after the choice became available in 1970 and thereafter. The reasons for this are personal and may not reflect the complexity of feelings about ethnic identity of the individuals who make this choice. If Alba and Islam's estimates are correct, underreporting by individuals themselves of an identity as a Latina/o is likely the largest source of uncertainty about the size of the population of Latina/o World War II veterans. Depending on how the analyst interprets the ethnicity of persons who choose not to 
Table 0.3. Percentage of Surviving Cohorts of Men Who Reported Service in the World War II Era: Pooled Censuses of 1980, 1990, and 2000

\begin{tabular}{|c|c|c|c|c|c|c|c|}
\hline \multirow[b]{2}{*}{$\begin{array}{c}\text { Age in } \\
1940\end{array}$} & \multicolumn{3}{|c|}{ Hispanics } & \multicolumn{4}{|c|}{ Ratio to Non-Hispanics } \\
\hline & U.S.-Born & $\begin{array}{c}\text { Puerto } \\
\text { Rico- } \\
\text { Born }\end{array}$ & $\begin{array}{l}\text { Immi- } \\
\text { grated } \\
\text { to U.S. } \\
\text { before } \\
\text { 1940* }\end{array}$ & $\begin{array}{c}\text { Non- } \\
\text { Hispanic, } \\
\text { U.S.- } \\
\text { Born }\end{array}$ & U.S.-Born & $\begin{array}{c}\text { Puerto } \\
\text { Rico- } \\
\text { Born }\end{array}$ & $\begin{array}{c}\text { Immi- } \\
\text { grated } \\
\text { to U.S. } \\
\text { before } \\
1940\end{array}$ \\
\hline $10-15$ & 38 & 11 & 46 & 51 & 0.75 & 0.22 & 0.90 \\
\hline $16-22$ & 60 & 26 & 53 & 73 & 0.82 & 0.36 & 0.73 \\
\hline $23-27$ & 39 & 16 & 41 & 46 & 0.85 & 0.35 & 0.89 \\
\hline $28-35$ & 21 & 7 & 20 & 25 & 0.84 & 0.28 & 0.80 \\
\hline
\end{tabular}

*Data for immigrants are from Census 2000 only. Margin of error for immigrants varies from \pm 5 to \pm 8 .

Source: U.S. Censuses of 1980, 1990, and 2000.

identify their Latino ancestry on a government form, an upward adjustment of the estimate presented here in the range of 10 to 20 percent may be warranted.

A second question that the census data can help us answer concerns the share of the World War II cohorts of Latinos who saw military service. Using the census data, we can calculate the percentage of Hispanic men from the age groups that provided the majority of service members during the World War II era and compare these to non-Hispanics. (Active duty service rates for women were approximately 1 to 2 percent of each age group, and group differences cannot be analyzed with much precision because of the small number of respondents who reported service.)

One's age at the start of the war is an important predictor of whether a man was called to active duty. The highest rates of service for all groups were for men between ages 16 and 22 in 1940 and thus (approximately) between ages 21 and 27 at the end of the war. Sixty percent of the Hispanic men who were natives of the U.S. mainland in this cohort reported World War II-era service at later censuses. This figure is approximately 20 percent lower than the service rate of non-Hispanic U.S. citizens in the same age cohort. This relationship between Hispanic and non-Hispanic service rates is similar across all cohorts.

As Table 0.3 shows, service rates were substantially lower for Puerto Ri- 
can men who were born in Puerto Rico than they were for mainland-born Hispanics. We do not have information from the censuses to fully explore this relationship; specifically, we do not have information about where the respondents lived during the wartime mobilization. However, the data appear to show that the key variable is geography, not ethnic origins. Puerto Rican men who were born on the U.S. mainland-and who likely lived on the U.S. mainland on Pearl Harbor day-served at a rate similar to Mexican Americans. It would appear that mobilization efforts in Puerto Rico, which did not yet have the Commonwealth status it would be granted in 1950, were less aggressive than the same efforts on the U.S. mainland.

Interestingly, we have no evidence that immigrant Hispanics who were already living in the United States at the start of the war served their country at lower rates than their native-born brethren. Service rates for immigrants are estimated with much less precision than for other groups because of the relatively small sample in the available census files, but these rates (see Table 0.3) are quite close to those of U.S.-born Hispanics. Of course, later years would see large new immigrant flows from Mexico, elsewhere in Central America, South America, and Cuba. These new postwar immigrants had not had the opportunity for active duty service in the U.S. military during the war.

The Latina/o population of the United States has both grown and diversified tremendously since the end of World War II. Latina/os-those who count themselves as such in responding to the census-in 2013 number more than 51 million and are the largest minority population in the United States. The largely Mexican American and Puerto Rican population of the period of the war has now been augmented by migration from throughout Latin America and by a high birthrate. The population has spread geographically throughout the United States, as well as throughout the U.S. social and economic structure. Knowing about the honorable service and sacrifices of as many as 400,000 Latina/o men and women in World War II helps us to understand the contributions of Latina/os to their country during a time of grave peril. Understanding the demographic parameters of this population helps us to know more about who they were and what they did. 
